\title{
Lack of leadership responsible for rising HIV infection levels in some provinces: HIV expert
}

A Canadian leader in the global fight against HIV/AIDS is chastising the federal government for failing to urge all jurisdictions to adopt the made-in-British Columbia approach to treating and preventing new infections, even as countries as diverse as China and the United States are rolling it out.

"We have developed a strategy centred around treatment and prevention that has worked remarkably well in British Columbia," says Dr. Julio Montaner, director of the BC Centre for Excellence in HIV/AIDS. "It hasn't worked around the country because there has been no leadership, federal or otherwise."

The Treatment as Prevention strategy has resulted in a $90 \%$ reduction in HIV-related mortality and morbidity in BC since the early 1990s. Adopting the strategy has also cut new HIV diagnoses to 236 in 2012, down from the 800 or more seen annually before 1996, according to the centre. That's the largest decline in the rate of new HIV diagnoses in all Canadian jurisdictions. Highly active antiretroviral therapy reduces viral loads, reducing the risk of HIV transmission by those infected.

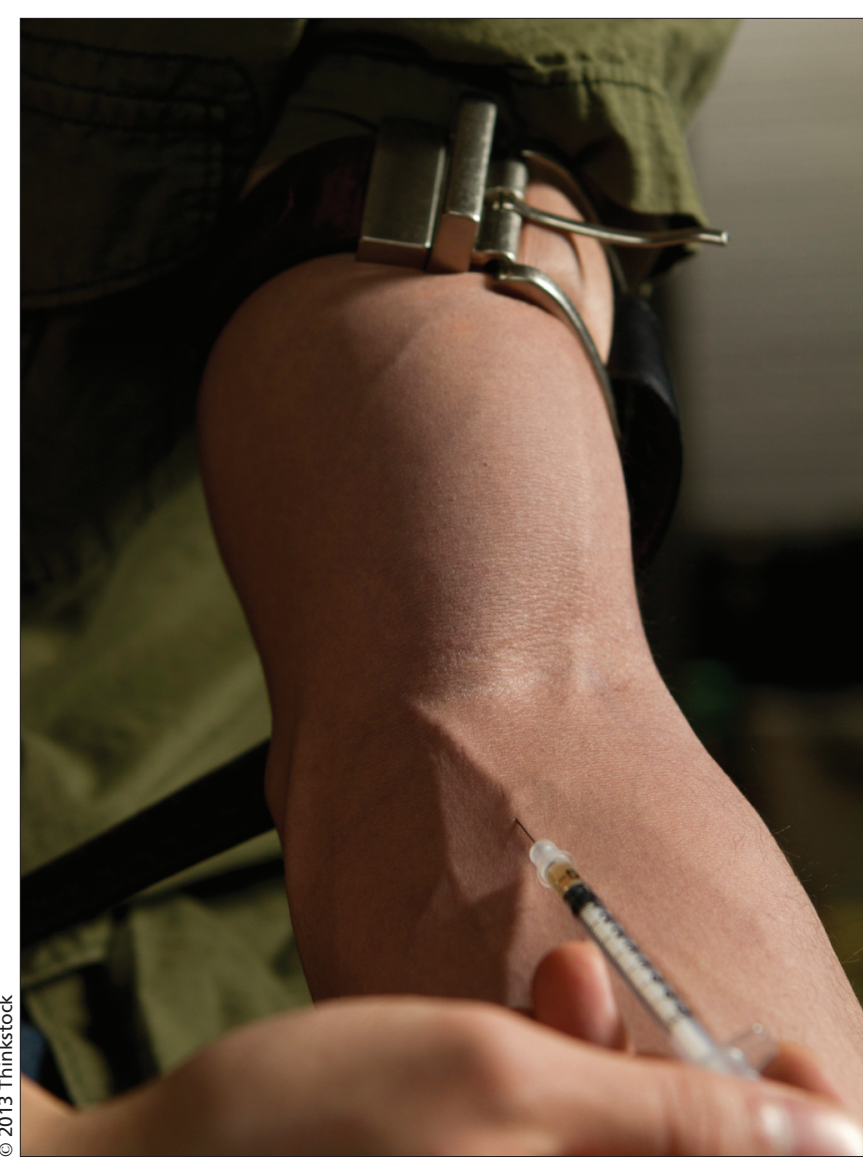

New HIV infections among injection drug users in British Columbia have declined from 352 in 1996 to just 29 in 2012. users are HIV positive, as well as First Nations communities. Mini-epidemics are also occurring among Aboriginal people in urban centres.

In Saskatchewan, rates of new HIV diagnoses increased nearly eight-fold

men, a group Montaner says they have not yet reached with an "appealing and palatable" prevention approach.

British Columbia's provincial government "has provided incredible leadership" in adopting the Treatment as Prevention strategy, says Montaner. He wants the provinces and the federal government to follow that example, pointing to the additional benefit of the money the health care system saves by averting new infections.

Despite yearly letters to Prime Minister Stephen Harper and successive federal health ministers requesting a meeting to discuss the $\mathrm{BC}$ approach and how to extend it across the country, Montaner says neither the Prime Minister's Office (PMO) nor the health minister has agreed to see him. In an Aug. 26 letter, a member of the PMO's correspondence staff wrote that Harper's "extremely demanding schedule" made it impossible for him to accommodate Montaner's meeting request. The letter then went to Health Minister Rona Ambrose's office, which has not responded.

In an emailed statement, the Public Health Agency of Canada appeared to cast doubt on the effectiveness of

New HIV infections among injection drug users in BC also declined. In 2012, there were just 29 new HIV diagnoses in this high-risk population, down from 352 in 1996.

Rates of new HIV infections are increasing, however, in Saskatchewan and Manitoba, and what Montaner calls "mini-epidemics" are emerging in pockets around the country. Those pockets include Ottawa, Ontario, where a substantial number of injection drug between 1995 and 2011, from 2.76 to 16.17 per 100000 , according to Montaner and colleagues (HIV Medicine;2013: 581-2). In Manitoba, rates increased to 6.53 from 4.52 per 100000 over the same period, with most of the new infections occurring among First Nations people.

Though BC has seen overall reductions, there remain increases in new infections among men having sex with the BC approach, suggesting that because of BC's "very comprehensive approach to reducing the HIV epidemic ... it is difficult to determine how much of the reduction can be attributed solely to the Treatment as Prevention Pilot at this time."

"More evaluation is needed to determine the feasibility, long-term sustainability, safety and effectiveness of new prevention technologies such 
as Treatment as Prevention in Canada and globally," Stéphane Shank, a senior media advisor at Health Canada, wrote to CMAJ. "The [Public Health] Agency [of Canada] continues to monitor the results of pilot studies and randomized controlled trials. Further, the Agency is examining ways to facilitate other demonstration pilots to assess reproducibility of the BC findings."

Despite a request from CMAJ, Health Canada did not comment on why neither the prime minister nor Ambrose has met with Montaner.

Meanwhile, Montaner says he has consulted with the White House, the UK parliament and China on how to bring Treatment as Prevention to their citizens. The World Health Organization has also recommended that countries adopt the strategy.

"What breaks my heart is that we know what needs to be done. It's a made-in-Canada strategy," Montaner says. "It's been adopted around the world, and the federal government doesn't want to talk about it because of prejudice and discrimination against the population most affected."
Like many of those involved in the fight against HIV/AIDS, Montaner was disappointed that Canada has not yet announced a new contribution to the Global Fund to Fight AIDS, Tuberculosis and Malaria. Montaner is calling on Canada to match, on a GDP-adjusted, population-based framework, the contribution of the five highest contributors to the Global Fund.

"If the United States has been able to find the money to support their contribution, and the UK has been able to do that, at a time in which both the UK and the United States are stressed quite significantly ... Canada, which has been laughing all the way to the bank ... has no right to walk away from the table and say 'We're not interested'," Montaner says.

The Global Fund will hold a replenishment conference in Washington, DC, in December to encourage countries to contribute to its US\$15billion goal for 2014-16. Although some nations have already made their contributions known, it is not unusual that Canada has not yet announced its commitment, according to Foreign
Affairs, Trade and Development Canada.

"Canada has supported the Global Fund since its inception and has consistently been a strong voice and active member of the Global Fund Board," according to Nicolas Doire, a media relations spokesperson for the department.

Since 2002, Canada has contributed more than US $\$ 1.5$ billion to HIV/AIDS assistance, Doire said in an email to $C M A J$. Canada contributed the majority of those funds - 65\% - to the Global Fund and UNITAID, and 35\% of contributions went directly to affected countries, according to the UNAIDS/ Kaiser Family Foundation's annual report. There has been no major discrepancy between the money Canada pledged and what it disbursed, according to Sophie Barton-Knott of the UNAIDS press office.

Canada will determine its support for 2014-16 as the replenishment conference approaches, Doire wrote. Laura Eggertson, $C M A J$

CMAJ 2013. DOI:10.1503/cmaj.109-4629 